\title{
Closure of a gastrotracheal fistula using a cardiac septal occluder device
}

Anastomotic leak is one of the most serious complications after esophagectomy, and it occurs in $5 \%-29 \%$ of patients [1]. Although there are no standardized methods for treating intrathoracic leakage, the treatment options include surgery, external drainage, and endoscopic treatment.

A 68-year-old man was hospitalized with a mild cough associated with oral intake. He had been diagnosed with squamous cell carcinoma of the esophagus 18 months earlier and underwent esophagectomy and gastric pull-up surgery. A chest computed tomography (CT) scan revealed a fistula between the left main bronchus and the neoesophagus ( $\bullet$ Fig. 1).

Treatment was attempted with an endoscopic clip, fibrin glue, and a clip with detachable snare, but the fistula remained open. Finally, the patient agreed to a treatment option using an Amplatzer MultiFenestrated "Cribriform" Septal Occluder (AGA Medical Corporation, Plymouth, Minnesota, USA). A guide wire was inserted into the esophagus, and we advanced an occluder over the wire. Once the proper position was confirmed, an interventional cardiologist released the device, first on the tracheal side and then on the gastric side ( $\bullet$ Fig. 2 ).

A barium study on day 5 showed complete fistula closure ( $\bullet$ Fig. 3), and an oral diet was tolerated.

At the 1-month follow-up, endoscopic evaluation confirmed stable fistula closure by the occluder.

Over the past decade, management of anastomotic leaks has shifted toward a more conservative approach, including the use of endoscopic clips, fibrin glue [2], and self-expanding stents [3]. However, in the present case, previously reported techniques failed to close the fistula. We therefore attempted an experimental approach using the atrial septal defect occluder. In our review of the literature, there are only two prior reports in which Amplatzer devices were used to close esophagotracheal and bronchoesophageal fistulas [4,5]. Although further studies are needed to establish the efficacy, the Amplatzer device could be considered in selected patients with anastomotic leakage.

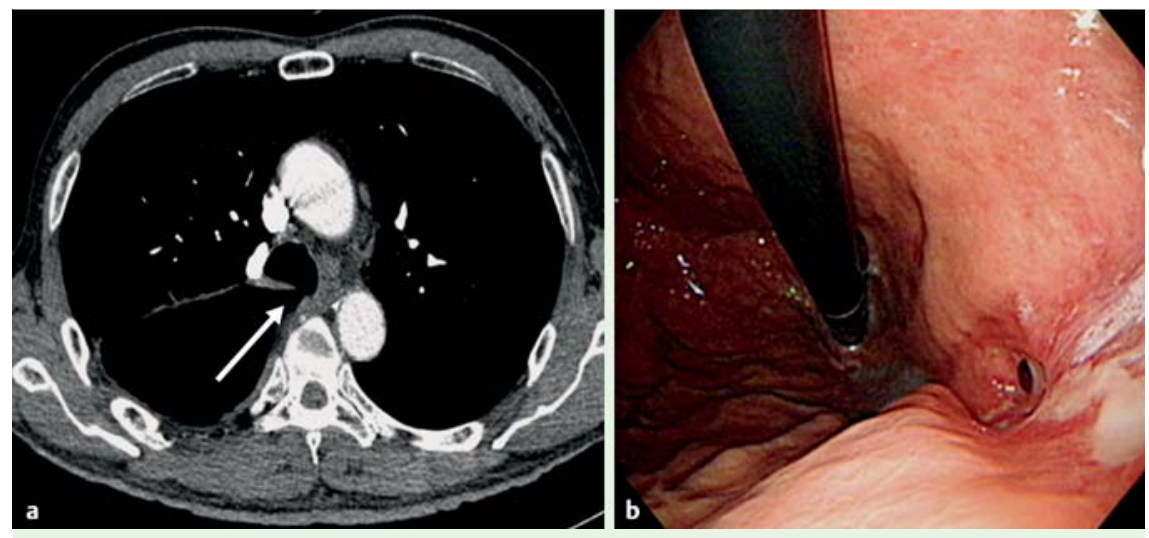

Fig. 1 a Chest computed tomography (CT) shows the fistula between the left main bronchus and the neoesophagus (arrow). b Endoscopy reveals a fistula in the upper body of the stomach.
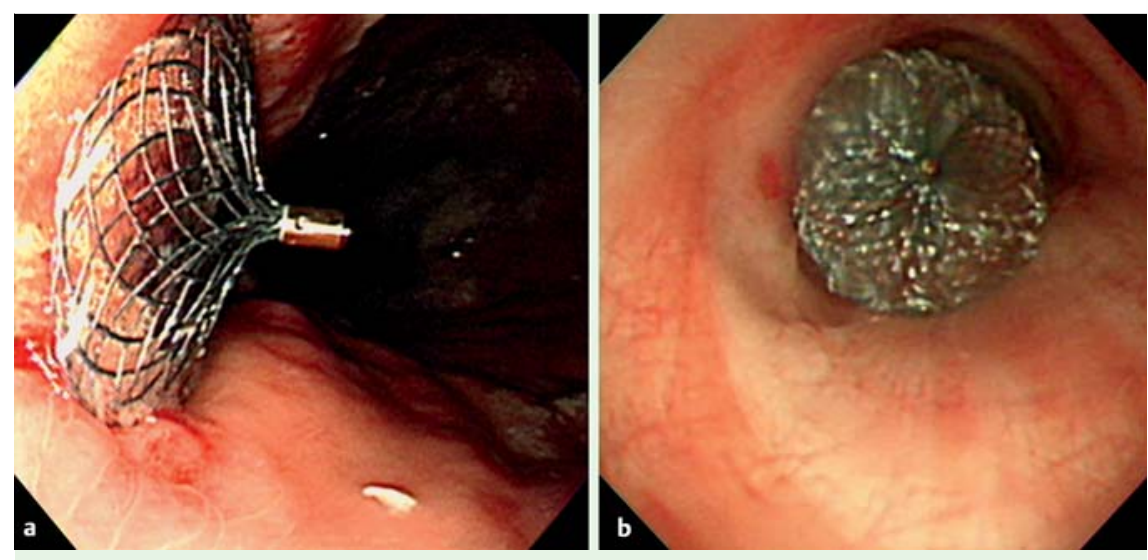

Fig. 2 a Endoscopic view and b bronchoscopic view of the occluder device after deployment.
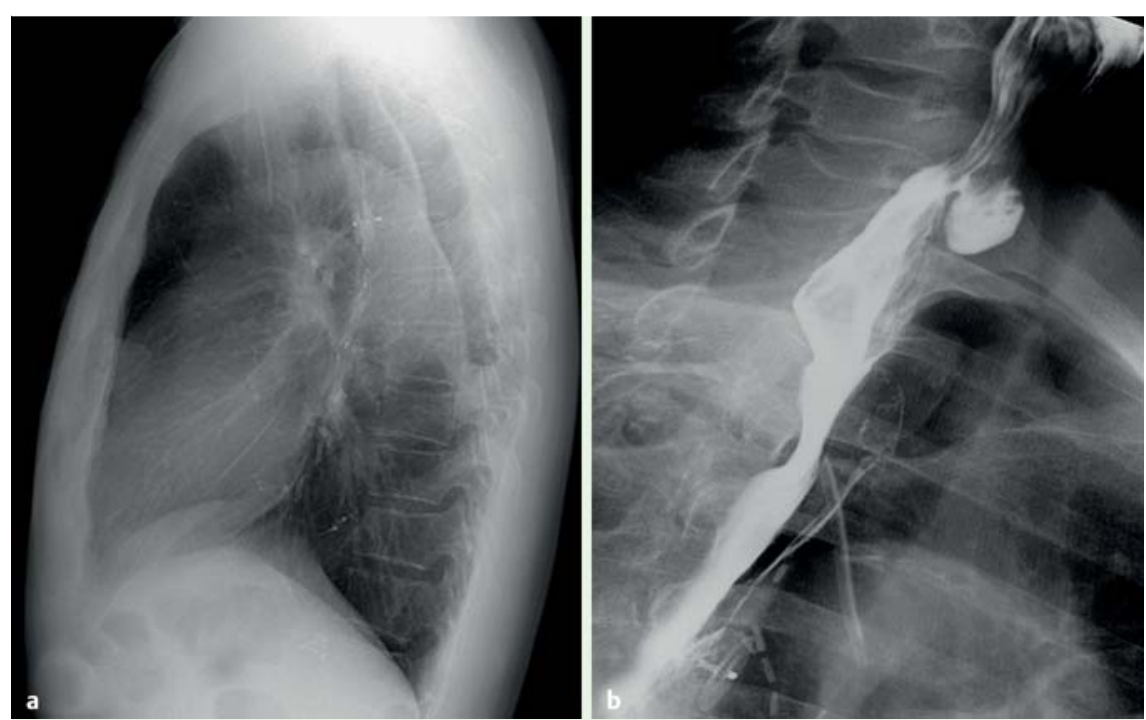

Fig. 3 a Chest radiograph showing that the occluder device is appropriately placed between the left main bronchus and the neoesophagus. b A Gastrografin study shows closure of the fistula 5 days after placement of the occluder. 


\section{Endoscopy_UCTN_Code_TTT_1AO_2AI}

\section{Competing interests: None}

H. J. Lee ${ }^{1}$, E. S. Jung ${ }^{1}$, M. S. Park ${ }^{1}$, H. S. Chung ${ }^{1}$, J. Y. Choi ${ }^{2}$, K. J. Lee $^{3}$, J. S. Lee ${ }^{4}$, H. K. Kil ${ }^{4}$, Y. C. Lee

1 Division of Gastroenterology, Institute of Gastroenterology, Department of Internal Medicine, Yonsei University College of Medicine, Seoul, Korea

2 Division of Pediatric Cardiology, Cardiovascular Center, Yonsei University College of Medicine, Seoul, Korea

3 Division of Pulmonology, Institute of Chest Disease, Department of Internal Medicine, Yonsei University College of Medicine, Seoul, Korea

4 Department of Anesthesiology and Pain Medicine, Anesthesia and Pain Research Institute, Yonsei University College of Medicine, Seoul, Korea

\section{References}

1 Urschel JD. Esophagogastrostomy anastomotic leaks complicating esophagectomy: a review. Am J Surg 1995; 169: 634-640

2 Bohm G, Mossdorf A, Klink C et al. Treatment algorithm for postoperative upper gastrointestinal fistulas and leaks using combined vicryl plug and fibrin glue. Endoscopy 2010; 42: 599-602

3 Schubert D, Scheidbach H, Kuhn R et al. Endoscopic treatment of thoracic esophageal anastomotic leaks by using silicone-covered, self-expanding polyester stents. Gastrointest Endosc 2005; 61: $891-896$

4 Repici A, Presbitero P, Carlino A et al. First human case of esophagus-tracheal fistula closure by using a cardiac septal occluder (with video). Gastrointest Endosc 2010; 71: 867-869

5 Green DA, Moskowitz WB, Shepherd RW. Closure of a broncho-to-neoesophageal fistula using an Amplatzer septal occluder device. Ann Thorac Surg 2010; 89: 2010-2012

\section{Bibliography}

DOI $10.1055 / \mathrm{s}-0030-1256058$

Endoscopy 2011; 43: E53-E54

(c) Georg Thieme Verlag KG Stuttgart · New York . ISSN 0013-726X

\section{Corresponding author}

\section{Y. C. Lee, MD, PhD}

Department of Internal Medicine Yonsei University College of Medicine 250 Seongsanno

Seodaemun-gu Seoul 120-752

Korea

Fax: +82-2-3936884

leeyc@yuhs.ac 